\title{
Abcesso do Espaço de Parona com Origem em Foco Sético Oral: Abordagem Multidisciplinar
}

\section{Parona Space Abscess Derived from Dental Disease: Multidisciplinary Approach}

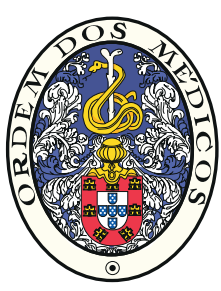

\author{
Luís FONSECA $\rrbracket^{1}$, Luís RIBEIRO2 ${ }^{2}$, Jorge PINHEIRO ${ }^{3}$, Ana GUERRA ${ }^{2}$ \\ Acta Med Port 2018 Jul-Aug;31(7-8):431-435 - https://doi.org/10.20344/amp.9932
}

\begin{abstract}
RESUMO
A infeção do espaço de Parona é uma patologia rara do antebraço. Reportamos um caso de um homem de 55 anos, com dor e impotência funcional na porção distal do antebraço, sem história de trauma, com uma semana de evolução. Associadamente, apresentava história de infeção odontogénica, síncrona com o início das queixas do antebraço, mas com resolução espontânea. A ecografia do punho documentou um abcesso, que foi prontamente drenado e o exame microbiológico demonstrou infeção por Streptococcus constellatus. A avaliação estomatológica revelou agudização sintomática de periodontite crónica no dente 2.7. O doente realizou a eliminação de focos séticos orais durante o internamento e teve alta com evolução favorável. As manifestações do quadro clínico e o agente isolado confirmam a origem odontogénica. Do que pudemos apurar, este é o primeiro caso publicado de um abcesso antebraquial odontogénico e demonstra a importância da eliminação sistemática de focos séticos orais na população geral.

Palavras-chave: Abcesso; Antebraço; Infecção Focal Dentária; Infecções Estreptocócicas; Periodontite
\end{abstract}

\section{ABSTRACT}

Parona Space infection is a rare forearm condition. We present a case of a 55-year-old male with pain and loss of function in the distal forearm for one week, with no previous history of trauma. Additionally, he presented a history of odontogenic infection, synchronous with the onset of the symptoms in the forearm, with spontaneous resolution. The wrist ultrasound found an abscess in the Parona space that was surgically drained. The bacterial culture test was positive for Streptococcus constellatus. Oral evaluation revealed symptomatic exacerbation in the upper left second molar of chronic periodontitis. Oral septic foci were eliminated and the patient had full recovery. Dental history, the bacteria isolated and the absence of trauma confirm the dental origin of the abscess. As far as the authors are aware, this is the first published case of an odontogenic forearm abscess. This case highlights the importance of systematic elimination of oral septic foci in the population.

Keywords: Abscess; Focal Infection, Dental; Forearm; Periodontitis; Streptococcal Infections

\section{INTRODUÇÃO}

A infeção do espaço de Parona é uma patologia rara, com potencial de morbilidade elevado, capaz de comprometer a viabilidade do antebraço, podendo levar até, em casos mais graves, à amputação do mesmo. ${ }^{1,2}$

O espaço de Parona é um espaço virtual profundo da região volar da extremidade distal do antebraço, entre a fáscia do músculo quadrado pronador e a bainha tendinosa sinovial dos músculos flexores profundos dos dedos e comunica com o espaço médio palmar da mão., ${ }^{2,3}$

Este tipo de infeção pode surgir como complicação de processos infeciosos da mão, tenossinovites dos tendões flexores, rutura volar de uma artrite radiocarpal, ou como infeção isolada. ${ }^{2,3,4} \mathrm{~A}$ etiologia é frequentemente traumática, por lesão penetrante cutânea, podendo ainda surgir por inoculação hematogénica. ${ }^{1}$ Os agentes etiológicos mais comuns são o Stafilococcus aureus e Streptococcus $\beta$-hemolíticos. ${ }^{1,3}$

Reportamos um caso de um abcesso do espaço de Parona, por Streptococcus constellatus, com origem odontogénica por via hematogénica.

\section{CASO CLÍNICO}

Doente do sexo masculino, 55 anos, dextro, com antecedentes de depressão, tabagismo e alcoolismo. Recorre ao Serviço de Urgência do Hospital de S. José por agravamento de dor e impotência funcional ao nível do terço distal do antebraço e punho direitos, um quadro com aproximadamente uma semana de evolução, sem história prévia de trauma ou intervenção cirúrgica, e sem queixas de alteração da temperatura corporal, arrepios ou suores noturnos. $O$ doente referia ainda história de odontalgia do segundo quadrante e tumefação da hemiface esquerda, síncronas com o início das queixas do antebraço, com resolução espontânea. Esta era a quarta vez que o doente se deslocava ao Serviço de Urgência durante esse período de tempo, tendo sido admitida uma celulite do membro superior, medicada com flucloxacilina, à qual se acrescentou metronidazol e anti-inflamatórios.

À observação no serviço de urgência o doente apresentava-se muito queixoso com edema e rubor da face anterior do terço distal do antebraço, punho e face palmar da mão, sem sinais de compromisso circulatório, não se objetivando soluções de continuidade cutâneas. Mobilização muito

1. Serviço de Estomatologia. Hospital de S. José. Centro Hospitalar de Lisboa Central. Lisboa. Portugal.

2. Serviço de Cirurgia Plástica e Reconstrutiva. Hospital de S. José. Centro Hospitalar de Lisboa Central. Lisboa. Portugal.

3. Unidade de Estomatologia Pediátrica. Hospital D. Estefânia. Centro Hospitalar de Lisboa Central. Lisboa. Portugal.

$\square$ Autor correspondente: Luis Fonseca. luisfilipefonseca@outlook.pt

Recebido: 13 de novembro de 2017 - Aceite: 20 de fevereiro de 2018 | Copyright $\odot$ Ordem dos Médicos 2018 


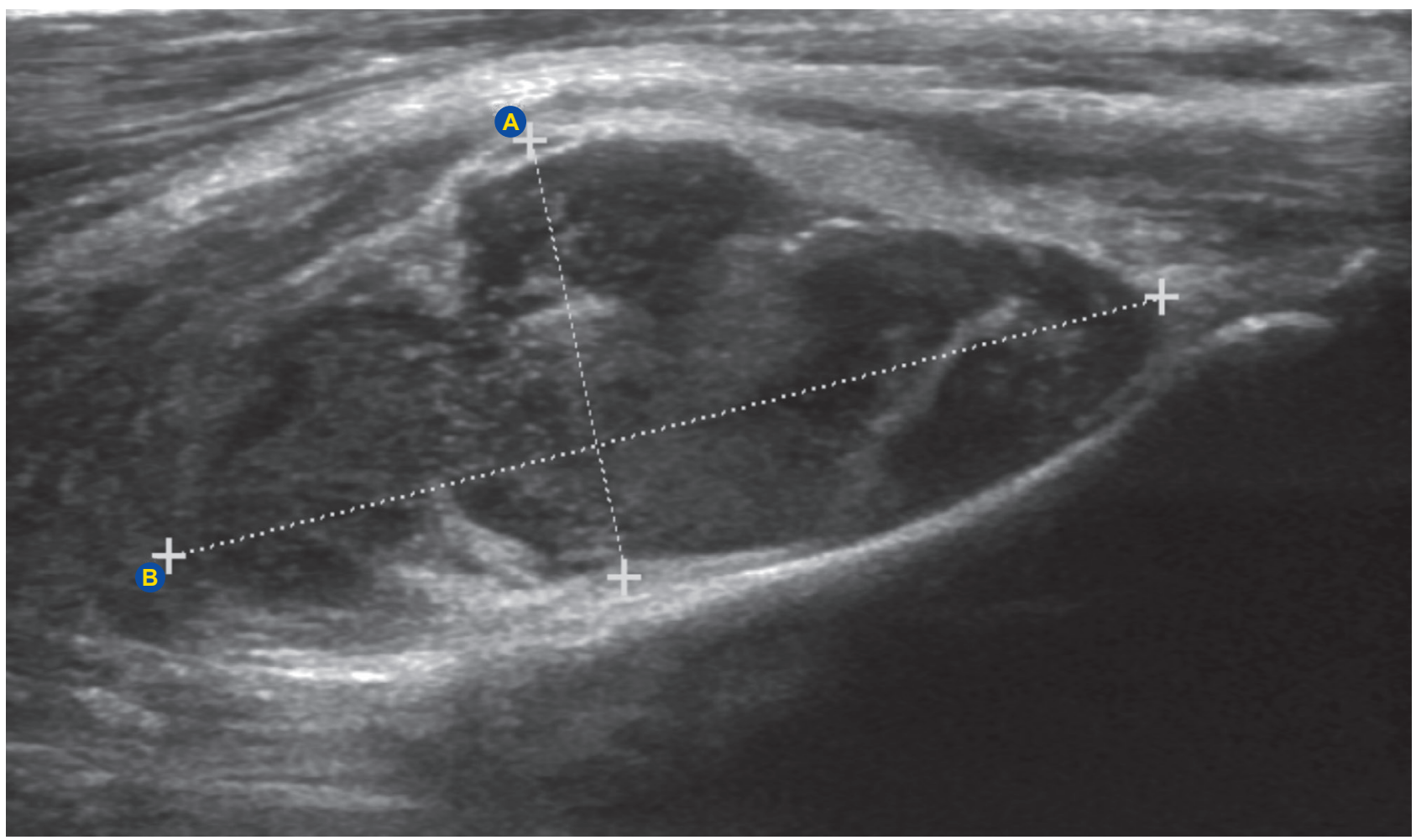

Figura 1 - Ecografia do antebraço com imagem de coleção líquida, heterogénea, de contornos lobulados, medindo 16,3 mm e 36,3 mm de eixos ântero-posterior (A) e longitudinal (B), respetivamente

limitada do punho e dedos e palpação dolorosa de toda a área atingida, com dor intensa à extensão passiva dos dedos. Analiticamente, apresentava leucocitose de 14,76 x 10\% (valores de referência: 4,5 - $11 \times 10^{9} / \mathrm{L}$ ), neutrofilia de $12,13 \times 10^{9} / \mathrm{L}$ (valores de referência: 2 - 8,5 x 10\%) e parâmetros inflamatórios com evolução desfavorável - proteína C-reativa de 130,9 mg/L (valor de referência < 5 mg/L).

Dada a presunção de infeção do espaço de Parona, pediu-se ecografia de partes moles que documentou uma imagem heterogénea medindo $36 \times 40 \times 16 \mathrm{~mm}$ de eixos longitudinal, transversal e ântero-posterior, respetivamente, subjacente às estruturas músculo-tendinosas, compatível com coleção abcedada do espaço de Parona, associada a ligeira tenossinovite dos tendões flexores comuns dos dedos (Fig. 1).

O doente foi rapidamente submetido a drenagem do abcesso, com lavagem profusa da loca através de incisão arciforme na face volar do antebraço com extensão ao punho e com abertura do ligamento anular anterior do carpo, constatando-se necrose de algum tecido muscular. Foi coIhido conteúdo purulento para cultura e antibiograma.

Durante o pós-operatório verificou-se regressão lenta, mas progressiva, dos sinais inflamatórios analíticos e clínicos. Ao terceiro dia a cultura revelou a presença de Streptococcus constellatus, tendo sido iniciada cefuroxima, de acordo com antibiograma, que completou 14 dias. $\mathrm{Na}$ avaliação estomatológica realizada durante o internamento o doente referiu história de odontalgias intermitentes dos primeiro e segundo quadrantes nos últimos três anos, não tendo realizado qualquer tratamento oral. Objetivamente, apresentava doença periodontal crónica generalizada avançada, raízes retidas, cáries dentárias e osteítes periapicais no terceiro quadrante à avaliação radiológica (Fig. 2). No segundo quadrante, o doente apresentava o dente 2.7 com mobilidade grau 2 (define-se como mobilidade dentária horizontal de um dente até $2 \mathrm{~mm}$, inclusive, numa classificação de 1 a 3 graus), recessão gengival, bolsas periodontais e dor à percussão. $\mathrm{O}$ doente foi submetido à extração do 2.7 (presumível dente causal da infeção à distância) e realizou a eliminação dos restantes focos séticos orais, com recurso a extrações múltiplas, encontrando-se agora a realizar tratamento periodontal e reabilitação protética (Fig. 3).

Algumas extrações foram privilegiadas em detrimento de determinados tratamentos endodônticos possíveis uma vez que a doença periodontal avançada subjacente a alguns dentes, associada ao perfil do caso, não nos oferecia prognóstico satisfatório.

Ao $12^{\circ}$ dia teve alta, clinicamente bem, a realizar fisioterapia para reabilitação motora do membro e com eferenciação para Infeciologia por achado laboratorial de hepatite $\mathrm{C}$. Dois meses após a intervenção cirúrgica apresentava uma franca melhoria do antebraço, com funcionalidade normal da mão e punho, sem limitações (Fig. 4).

\section{DISCUSSÃO}

O Streptococcus constellatus é um agente patogénico comum da cavidade oral, em particular na doença periodontal. ${ }^{5} \mathrm{O}$ conjunto da história estomatológica do doente, o agente microbiano isolado e a ausência de trauma 


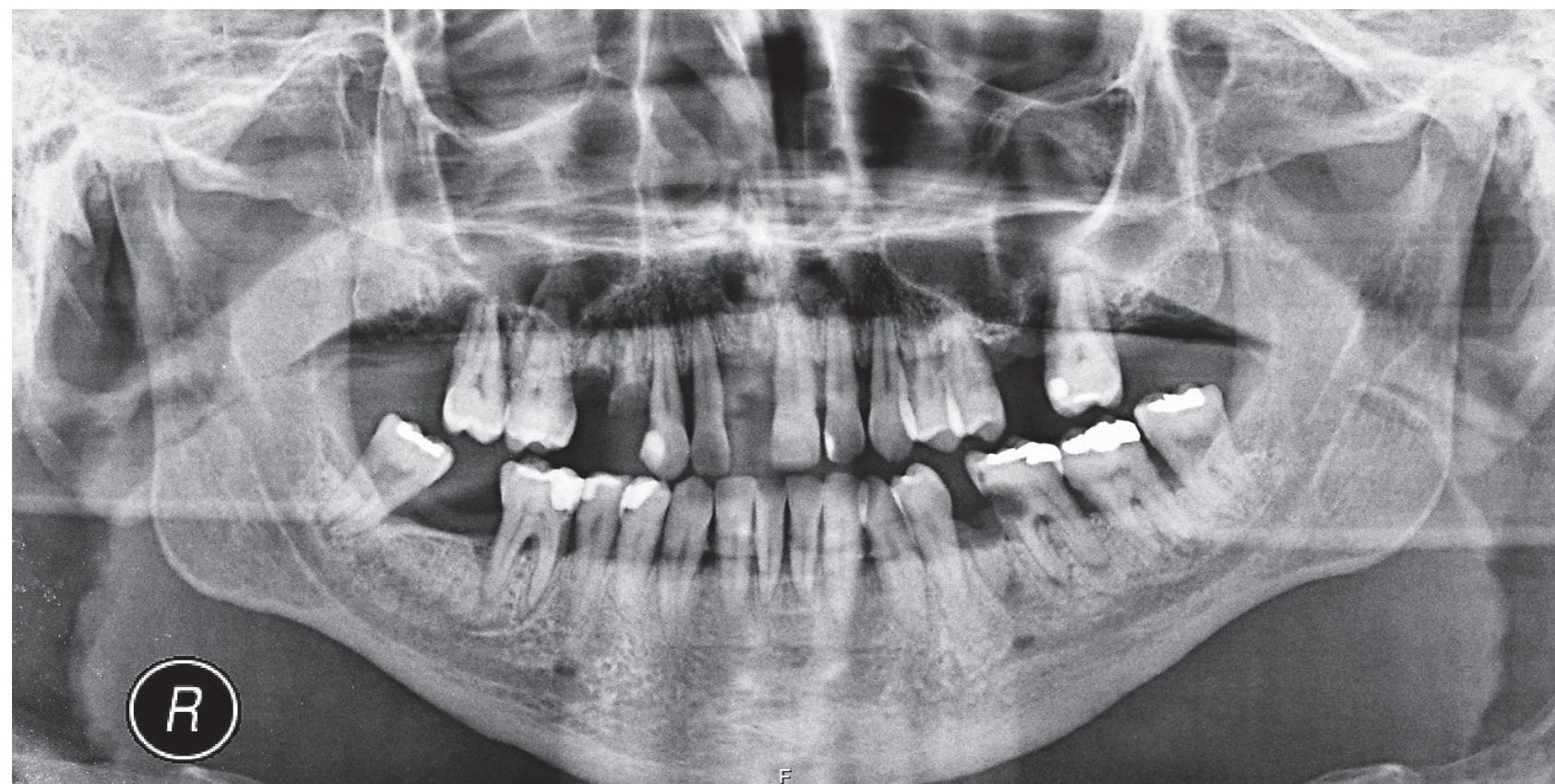

Figura 2 - Ortopantomografia com evidência de reabsorção óssea alveolar horizontal generalizada, reabsorção óssea vertical mesial e distal de 27, hipertransparências nos ápices de 3.5, 3.6 e 3.7, raízes retidas nos primeiro e terceiro quadrantes e cárie corono-radicular perfurante de 3.6

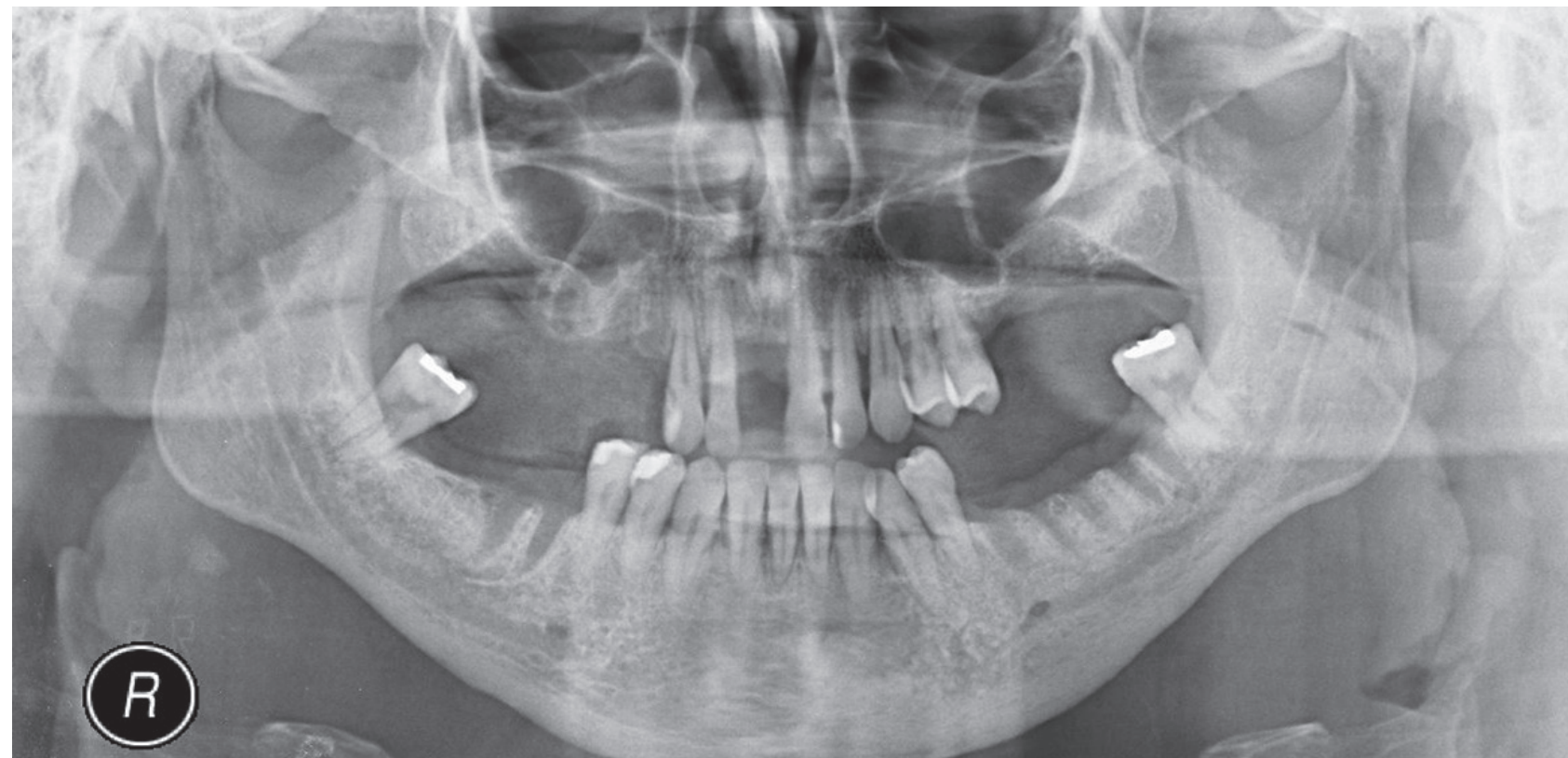

Figura 3 - Ortopantomografia de reavaliação, após eliminação de focos séticos orais, com extrações sequenciadas dos dentes 1.6, 1.7, 2.7, 3.6, 3.7, 4.6 e restos radiculares de $1.4,1.5$ e 3.5 .

pregresso do antebraço, confirmam a origem odontogénica do abcesso do espaço de Parona. Após pesquisa bibliográfica no PubMed e Web of Science não encontrámos nenhum caso publicado de um abcesso antebraquial odontogénico. As infeções do espaço de Parona podem ser subtis e sub-diagnosticadas num estádio inicial. ${ }^{1,2}$

Uma drenagem cirúrgica urgente com cultura bacteriológica, antibioterapia empírica de largo espetro com cobertura de cocos gram-positivos e fisioterapia precoce são o tratamento recomendado..$^{1,2,3}$

Este caso demonstra a importância da eliminação sistemática de focos séticos orais na população geral (não exclusivamente em doentes de risco), para a prevenção e tratamento de quadros infeciosos agudos, não só locais e regionais, bem como infeções metastáticas decorrentes de bacteriémias de processos odontogénicos. Outras formas existem, mais comuns e amplamente conhecidas, de disseminação hematogénica de infeções à distância de origem oral, incluindo em doentes imunocompetentes, como a endocardite bacteriana ou a infeção de próteses articulares. ${ }^{6,7}$

O caso realça, ainda, a importância crescente de uma abordagem multidisciplinar no diagnóstico e tratamento de qualquer patologia. 

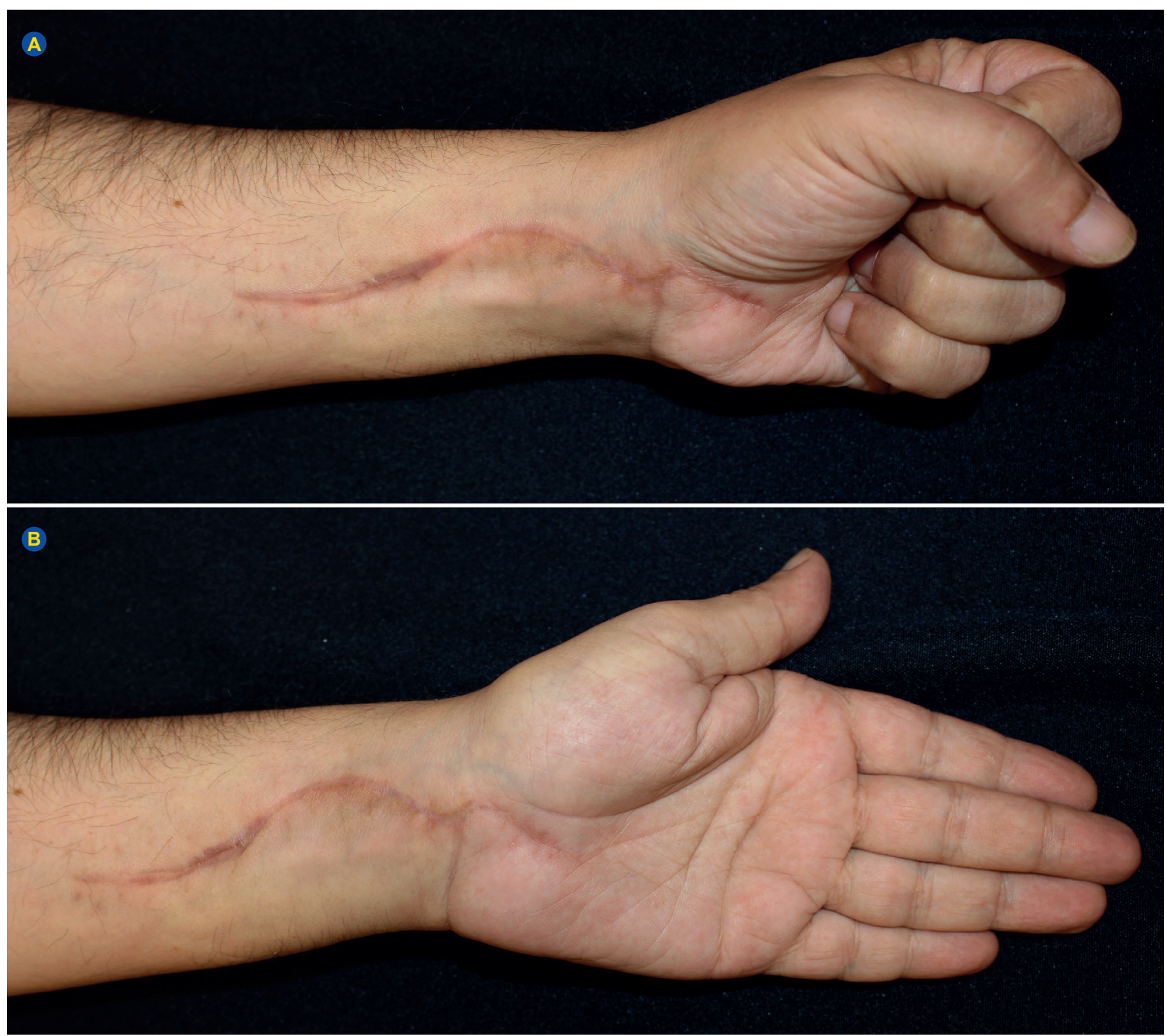

Figura 4 - Fotografia de seguimento do antebraço e mão, com 3 meses de pós-operatório, em flexão (A) e extensão da mão (B)

\section{CONCLUSÃO}

O caso clínico descreve um diagnóstico, ao que sabemos, único de uma infeção à distância de origem odontogénica mas, acima de tudo, põe em relevo a necessidade das prevenções primária e secundária em saúde oral, bem como os benefícios das abordagens multidisciplinares dos doentes.

\section{PROTEÇÃO DE PESSOAS E ANIMAIS}

Os autores declaram que os procedimentos seguidos estavam de acordo com os regulamentos estabelecidos pelos responsáveis da Comissão de Investigação Clínica e Ética e de acordo com a Declaração de Helsínquia da Associação Médica Mundial.

\section{REFERÊNCIAS}

1. Sharma KS, Rao K, Hobson MI. Space of Parona infections: experience in management and outcomes in a regional hand centre. J Plast Reconstr Aesthet Surg. 2013;66:968-72.

2. Jamil W, Khan I, Robinson P, Thalava R. Acute compartment syndrome

\section{CONFIDENCIALIDADE DOS DADOS}

Os autores declaram ter seguido os protocolos do seu centro de trabalho acerca da publicação de dados.

\section{CONSENTIMENTO DO DOENTE}

Obtido.

\section{CONFLITOS DE INTERESSE}

Os autores declaram não terem qualquer conflito de interesse relativamente ao presente artigo.

\section{FONTES DE FINANCIAMENTO}

Não existiram subsídios ou bolsas que tenham contribuído para a realização do trabalho.

of the forearm secondary to infection within the space of Parona. Orthopedics. 2011;34:e584-7.

3. Patel DB, Emmanuel NB, Stevanovic MV, Matcuk-Jr GR, Gottsegen CJ, Forrester DM, et al. Hand infections: anatomy, types and spread 
of infection, imaging findings, and treatment options. Radiographics. 2014;34:1968-86.

4. Osterman M, Draeger R, Stern P. Acute hand infections. J Hand Surg Am. 2014;39:1628-35.

5. Gomes BP, Berber VB, Kokaras AS, Chen T, Paster BJ. Microbiomes of endodontic-periodontal lesions before and after chemomechanical preparation. J Endod. 2015;41:1975-84.
6. Wu PC, Tu MS, Lin PH, Chen YS, Tsai HC. Prevotella rrain abscesses and stroke following dental extraction in a young patient: a case report and review of the literature. Intern Med. 2014;53:1881-7.

7. Seppänen L, Lauhio A, Lindqvist C, Suuronen R, Rautemaa R. Analysis of systemic and local odontogenic infection complications requiring hospital care. J Infect. 2008;57:116-22.

$$
\begin{aligned}
& 20 \\
& \text { dist } \\
& \text { ex } \\
& \text { pre }
\end{aligned}
$$

Palavras-chave: Enfisema Mediastínico; Enfisema Subcutâneo; Extração Dentária

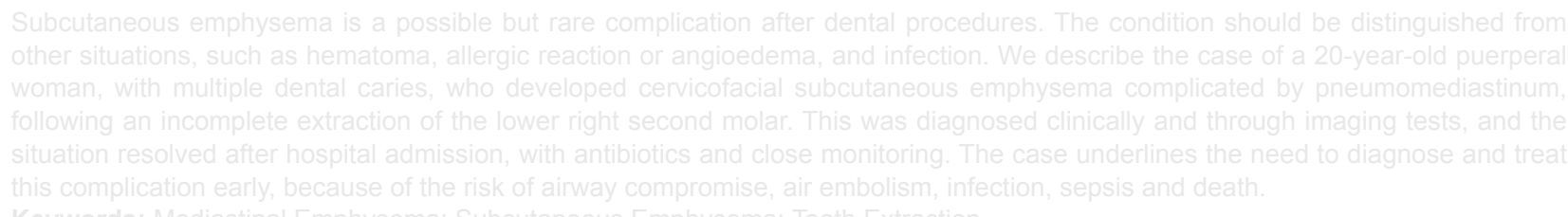

Keywords: Mediastinal Emphysema; Subcutaneous Emphysema; Tooth Extraction

INTRODUÇÃO 